\title{
EXPERIMENTAL STUDY OF BEHAVIOUR OF POULTRY FEATHER FIBER - A REINFORCING MATERIAL FOR COMPOSITES
}

\author{
K B Jagadeeshgouda ${ }^{1}$, P Ravinder Reddy $^{2}$, K Ishwaraprasad $^{3}$ \\ ${ }^{1}$ Assistant Professor, Dept of Mech Engineering S G Balekundri Institute of Technology Belgaum and Research scholar \\ JNTUH, India \\ ${ }^{2}$ Professor and Head, Department of Mechanical Engineering, CBIT Hyderabad -75, AP, India \\ ${ }^{3}$ Professor, Department of Mechanical Engineering \& Director of evaluation, J N T U Hyderabad, India
}

\begin{abstract}
Currently, the abundant quantity of chicken feather produced annually by the poultry industry as a waste in worldwide, is a serious solid agricultural waste problem. The traditional disposal strategies of chicken feather were not environmental friendly. Exploitation of secondary application alone is not a solution to the problem of environmental; also it enhances the commercial value of feathers. In this study, a review on the behaviour of the chicken feather fibers was made to understand their usability as a reinforcing material for composite fabrication. Fibers of some critical length were estimated experimentally and calculated relative density. Tensile property of fiber, dimensional and strength of the quill was estimated. It was observed that, the quill diameters were varying with length, and all of them were not weighing same. Chemical resistivity and burning tests were conducted, and results were reported. Morphology of the nonwoven mats was studied.
\end{abstract}

\section{INTRODUCTION}

Natural fibers have been used to reinforce materials for over thousand years. Recently, they have been employed in combination with plastics. Natural fibers are environmentally friendly, fully biodegradable, abundantly available, renewable and cheap and have less density. Natural fibers pose no health hazards and, finally, provide a solution to environmental pollution by finding new uses for waste materials. Currently, many types of natural fibers have been investigated for use in plastics including flax, hemp, jute straw, wood, rice husk, wheat, cane (sugar and bamboo), grass, reeds, kenaf, ramie, oil palm empty fruit bunch, sisal, coir, water, hyacinth, pennywort, kapok, banana fiber, pineapple leaf fiber. Fibers obtained from the various parts of the plants are known as vegetable fibers. Animals can also provide a source of fibers. Natural fibers are emerging as a viable alternative to manmade fibers, particularly in automotive, packaging, building, and consumer product industries, and becoming fastest growing reinforcing material. A wide variety of properties can be achieved through proper selection of fiber type, fiber orientation and fiber reinforcement form. [1]. Natural fibers can be obtained from animals too. Reports on using animal fibers as reinforcing fibers are rare. Currently, the abundant quantity of poultry feathers produced annually by the poultry industry as a waste which can be effectively used as a reinforcing material. Around 24 billion chickens are killed per year across the world, which are discarded around 8.5 billion tons of feathers, in which India's contribution alone is 400 million tonnes.India was ranked the fifth largest poultry producer in the world[2]. Poultry feathers are approximately
$91 \%$ protein (keratin), $1 \%$ lipids, and $8 \%$ water [3]. The amino acid sequence of a poultry feather is very similar to that of other bird's feather. Chicken feathers are approximately half feather fibre and half quill (by weight). The feather fibre and quill are both made from hydrophobic keratin, a protein that has strength similar to nylon and a diameter smaller than wood fibre[4]. The fibre is more durable and has a higher aspect ratio than the quill. Feathers can't be taken from the chicken and made directly into new materials. The stiff central core of the feather (quill) must be stripped of from the barbs. This soft barb material can be used as reinforcing material. Although the whole feather is made of keratin, the crystal structure of the protein in the brittle central quill is different from that in the soft but durable barbs; only the barbs have the desirable properties [5]. Feather barbs are too short to allow them to spun into thread and woven into cloth, but they can be mixed with man-made materials to prepare slab or mat of randomly oriented type. The length of the barbs is depending on the region location along the rachis. The barbs located at the base of the rachis are so long than those at the tip. A physical and mechanical property of the chicken feather depends upon the percentage of keratin protein present, which generally varies with ecological condition of the bird [5-9]. To aid the development of successful applications for poultry feather fiber in composite making; this work has been taken up. The objective of this investigation is to develop processing and testing of both fiber and quill. Also, attempt has been made to prepare a nonwoven mat form feather fiber using papermaking and spray bonded technique. 


\section{EXPERIMENTAL APPROACH}

\subsection{Cleaning of Feathers}

Broilers are chickens both male and female that will be slaughtered for meat at about 5 to 8 months old depending on weight and layers are produced to lay eggs then moved for slaughter. In the present work, the required raw material was obtained from Boiler chicken after processing for meal. Feathers (CF) directly collected from a chicken processing plant or slaughterer are always dirty and contain various foreign materials, such as skin, blood, feces and flesh. Initially feathers were washed many times with hot water with detergent and dried. After drying quills were separated by stripping from barbs, since they differ physically. Initially barbs were mechanically treated to convert them into wool form and used suitable straining device to separate out coarser elements. Then the fibers are cleaned in running water and dried. A solution was prepared in a glass beaker by adding $6 \%$ $\mathrm{NaOH}$ to distilled water. Mechanically treated and dried fibres were soaked in a solution for three hours and then washed in running water. These were dried for 10 hours in natural light. These barb fibres were used for estimating physical properties like density, aspect ratio and strength. Advantage of chemical treatment (with $\mathrm{NaOH}$ ) is to remove moisture content from the fibres thereby increasing its strength. Also, chemical treatment enhances the flexural rigidity of the fibres and stabilizes the molecular orientation. Figure-A1 represents the technique used in the laboratory so as to process the raw poultry feathers into useful fibers for further processing [10, 11]. Figure-A2a and $\mathrm{A} 2 \mathrm{~b}$ shows the terminology of the feather and cross sectional view of single barb.

\subsection{Calculation of Apparent Density of Fiber}

It has been reported that the density of chicken feather fibre, provided by Tyson Foods, Inc., is $0.8 \mathrm{~g} / \mathrm{cm} 3$. This value is interpreted as an apparent density value because it is not the weight of a solid matter, but instead it is the weight of a volume of both solid matter (the walls of fiber) and air (the hollow inside the fiber). Hong and Wool reported a typical value of $8 \mathrm{~mm}$ for fiber length [1]. Barone and Schmidt [12] measured the density of chicken feather fiber, obtained from feather fiber Corporation, by displacing a known volume and weight of ethanol with an equivalent amount of fiber. They reported a value of $0.89 \mathrm{~g} / \mathrm{cm} 3$ for the chicken feather fiber. Barone and Schmidt reported fiber lengths of 3.2-13 mm. In the present work, fibre is being used for further investigation of some critical length by neglecting the void inside the fibers were estimated experimentally and calculated relative density using a formula

$$
\text { Density }(\rho)=\text { Mass }(\mathrm{m}) / \text { volume (V)---Eq.No } 1
$$

\subsection{Aspect Ratio of Feather Fibers}

A fiber is characterised geometrically not only by its very high length-to-diameter ratio but by its near crystal sized diameter. Strength-to-density and stiffness-to-density ratios are commonly used as indicators of the effectiveness of a fiber, especially in weight-sensitive applications like aircraft and space vehicles. Barone and Schmidt [12] examined chicken feather fiber from Feather fiber Corporation. Barone and Schmidt found that fibers had a constant diameter of approximately $5 \mu \mathrm{m}$ and lengths between 3.2 and $13 \mathrm{~mm}$. These values correspond to aspect ratios of 600-2600. Kar and Misra [13] measured by scanning electron microscopy the diameter of chicken down feather fibers obtained from MaXim LLC. Fiber diameters were found to be in the range of $5 \mu \mathrm{m}$.Dweib et al. [14] examined chicken feather fiber from Feather fiber Corporation. These fibers were reported to have diameters of $6-8 \mu \mathrm{m}$ and lengths of 3-13 mm. These values correspond to aspect ratios of 400-2200. Values for chicken feather fibers obtained from Tyson Foods, Inc. was reported by Hong and Wool [1]. Hong and Wool reported typical values of $6 \mu \mathrm{m}$ for fiber diameter, $8 \mathrm{~mm}$ for fiber length, and 1000 for fiber aspect ratio. In the present work author measured the diameter of the down feather barbs obtained from local slaughter by optical microscope. Average diameter was found to be in the range of 5-6 $\mu \mathrm{m}$ and length of 3$22 \mathrm{~mm}$. These values corresponding to aspect ratio of 600 3667.

\subsection{Fiber Strength}

Authors measured the tensile strength of chicken feather fiber directly. Fibers were held by adhesive tape and tested in tension with a crosshead speed of $1.3 \mathrm{~mm} / \mathrm{min}$. Fiber diameter was measured with an optical microscope and used to determine fiber area. Fiber area was estimated in the range of 1. $9635 \times 10^{-5}-2.827 \times 10^{-5} \mathbf{m m}^{2}$. Author has reported that strength results varied due to the heterogeneity of the fibers. Strengths ranged from 40-123 Mpa. Tensile test was conducted on a universal testing machine (Instron Model 5565 ) of $0-500 \mathrm{Kg}$ capacity.

\subsection{Tensile Test of Quill}

Feathers quill must bend under the aerodynamic forces generated during flight while also being very lightweight. The mechanical properties of chicken feather are related to the structure of natural protein or keratin present in feather. Keratin, like other biological polymers, possesses a structure with covalent bonds that transfer forces while only negligibly distorting. Strains are largely produced by changes in the hydrogen bonds, van der Waals, and Coulombic interactions. According to Feughelman [15], consistency among natural protein fibers results in similar moduli of elasticity. However, Bonser and Purslow's [16] summary of studies since 1966 reports moduli of elasticity for feather keratin ranging from $0.045 \mathrm{Gpa}$ to $10 \mathrm{Gpa}$. Bonser and Purslow [16] performed uni- 
axial tension tests on $25 \mathrm{~mm}$ sections of keratin cut from the rachis dorsal surface of flight feathers from different species. The Young's modulus was found to be approximately $2.5 \mathrm{Gpa}$ for all species. Bonser and Purslow also found the Young's modulus to increase markedly along the length of the rachis, with the highest values at the feather tip. To explain this, they considered a swan's primary feather to act as a simple airfoil in a laminar flow. Since the drag profile is proportional to the thickness/diameter of the rachis, an increase in flexural strength towards the tip would allow for a smaller shaft diameter.Cameron et al. [17] confirmed that the mechanical properties of feather keratin vary appreciably along the length of the rachis. The swan and goose feathers both proved to be functionally gradient, with Young's modulus varying from 2.5-3.0 Gpa at the calamus to 4.5-5.0 Gpa at the rachis tip. The ostrich feathers had a significantly lower modulus and did not show an increase along their length. George et al. [18] studied turkey feather fiber properties for fibers at different positions along the rachis. It was found that both the tenacity and modulus of turkey feather fiber, increased with the distance from the calamus. Purslow and Vincent [19] measured the elastic modulus of feather rachis from pigeons, with and without inner quill. Dehydrated feather rachises were tested in bending. Elastic modulus values for the rachis with inner quill were greater than values for rachis without inner quill.

\subsubsection{Dimensional Test of the Quill}

Feathers spread over the bird are varying in size depends upon the location. Based on the location; feathers are identified as primary and secondary feathers. Primary feathers are at the region of the wings and are not in uniform size. To optimise weight and diameter author has taken this work. In this test author estimated the average weight of the quill by selecting samples. These samples were weighted in weighing machine of model No 7301A in a laboratory. Using Mitutoyo Digimatic micrometer (Fig.A3) the dimensions of the quill along the length was estimated. Along the length of the specimen, we marked four locations at a specific distance for measurement purpose. Table- B2 represents the recorded readings.

Tensile test was carried out according to ASTM test standards D 638 in the universal testing machine for quill (shaft) portion to estimate average strength. Figure A4 (a) represents the arrangement for tensile test and Figure A4 (b) represents load verses deflection of quill portion. Test results are shown in Table -B3.

\subsection{Chemical Test of Quill and Barbs}

Quill and barb fiber samples those harvested for a month were tested with $2 \% \mathrm{Na}_{2} \mathrm{CO}_{3}, 1 \% \mathrm{Hcl}$ and $5 \% \mathrm{NaOH}$ for the duration of $2 \mathrm{hrs}, 8 \mathrm{hrs}$ and $24 \mathrm{hrs}$. Fig-A5 represents an experimental arrangement for the test. After 24 hours of drying at room temperature, they were reweighted. Average observations are tabulated in Table-B 4

\subsection{Burning Test}

This test was conducted to know the behaviour of the feather and the quill when they are subjected to fire and high temperature. Table-B5 represents the observations during the test.

\section{PREPARATION OF FEATHER FIBER MAT OF NON-WOVEN TYPE}

An average length of the barbs is about $6-22 \mathrm{~mm}$, so it was difficult to prepare either a yarn or weaving, hence chopped mat concept was used to obtain the nonwoven mats,

that provide equal strength in all directions. Initially, mechanically treated fibers were socked in a corn starch solution prepared with a known quantity of water for 30 minutes under room temperature and then using papermaking technique sheets of required size had produced, and then laid on wax coated aluminium foil. It was allowed to dry naturally for $24 \mathrm{hrs}$ and then hot pressed in a hydraulic press with a heating system and later trimmed to the required size.[20-23] Also, non-woven mat had produced by spray bonding technique using PVA. Trials were made to blend the chicken feather fiber with grass pulp and paper pulp to make nonwoven mat and got a good result [24-27]. Fig A6\& Fig A7 represents the stages of manufacturing non-woven mats of respective technique.

\section{RESULTS AND DISCUSSION}

\subsection{Assessment of Apparent Density}

Hence it is observed that, average recorded relative density of the barbs is $0.7 \mathrm{gms} / \mathrm{cc}$. The difference in results may be related to composition differences between the chicken feather fibres samples studied. The hollows, or voids, inside chicken feather fibres may become more accessible to air or any fluid as fibre length decreases. From Table-B1, it was observed that, chicken feather fiber has shown very close values of apparent density in both trials in the range of $0.677-0.72 \mathrm{~g} / \mathrm{cc}$. Compared with other animal and plant fibers, like silk $1.17 \mathrm{~g} / \mathrm{cc}$, wool $1.31 \mathrm{~g} / \mathrm{cc}$ and cotton $1.5-1.6 \mathrm{~g} / \mathrm{cm} 3$, jute 1.3 $\mathrm{gm} / \mathrm{cm} 3$, coir $1.2 \mathrm{~g} / \mathrm{cm} 3$ etc density of chicken feather fiber was observed less. Thus, chicken fiber inclusion in a composite could potentially lower composite density, whereas the density of a typical composite with synthetic reinforcing increases as fiber content increases. Thus, substantial savings, in terms of transportation and construction costs, could be derived from the use of lightweight composites containing chicken fiber.

\subsection{Assessments of Aspect Ratio and Fiber Strength}

Usually ends of fibers have lower load carrying ability and hence higher the ends lower will be the load carrying capacity of the composite. Longer the fiber, number of ends will be less and hence higher will be the load carrying capability. In general strength of the composite is decided by the critical 
length of the fiber. If the length of the fiber is longer than the critical length; strength of the composite will be higher. Another factor which decides the strength of the composite is the aspect ratio $(1 / \mathrm{d})$.If the aspect ratio is greater than 15 , the fiber is termed as continuous, and otherwise it is termed as discontinuous [29].

It was observed that, diameter and length of fibers were varying from location to location, so, average aspect ratio was greater than 15, hence chicken feather fibers are considered as continuous. Since chicken feather fibers are naturally smaller in length which accommodates more number of fibers for the same volume fraction, hence increase in surface area and number of flaws (defects) reduced which intern improves the efficiency of load transfer ability.

\subsection{Assessment of Tensile Strength}

From the Table-B2 it was cleared that, all samples measured different diameters at different location of each samples, also, measured different length and weight. From the Fig-A4b it was observed that, all quill samples behaves like an elastic material, and also it was observed that, material having good stiffness since, it has represented very less elongation. From the Table- B3 it was observed that from the 5 samples, maximum young's modules were $363.9 \mathrm{Mpa}$ and the minimum was $173.4 \mathrm{Mpa}$, this difference might be due to variation in the cross-sectional area of an individual quill. In most of the applications uniform fiber cross section and its length is very important to distribute load uniformly, hence, quill can't be used directly as a reinforcing material.

\subsection{Assessment of Chemical Resistance and Burning}

\section{Test}

Moisture sensitivity is one of the most serious problems of natural fiber, and natural fiber reinforced composites whereby these fibers swell and rot. Hence, quill and barb fiber samples those harvested for a month were tested with $2 \% \mathrm{Na}_{2} \mathrm{CO}_{3}$, $1 \% \mathrm{Hcl}$ and $5 \% \mathrm{NaOH}$ for the duration of $2 \mathrm{hrs}$, $8 \mathrm{hrs}$ and $24 \mathrm{hrs}$.It was observed that, quill weight was increased by $35 \%-40 \%$ and also, barbs weight was increased by $58 \%-65 \%$ in all reagents except in $5 \% \mathrm{NaOH}$. Since feathers are naturally porous, they can be used as fluid absorbers. After 24 hours of drying at room temperature, they were reweighted and found losses in weight. From the Table-B4 also, it was cleared that, quill looses less weight than barbs, but quill completely dissolved in $5 \% \mathrm{NaOH}$ after $24 \mathrm{hrs}$, but barbs looses its weight and became brittle. Treating fibers with $\mathrm{NaOH}$ is essential for enhancing some of the properties but it is not recommended to treat them for more then 1 hour to maintain stability in the fibers. Average observations are tabulated in Table-B4.Burning is one of the traditional disposing methods of chicken feather fibers, so to understand it environmental effect burning test was conducted separately on barbs and quill in a laboratory on a selective quantity of
samples.From the Table-B5, it was observed that, quill burns continuously with burning rubber odour left with black soft ash, whereas barbs completely fuses and has not supported continuous burning but liberated odour like burning human hair

\subsection{Assessment of Nonwoven Manufacturing Process}

\section{and its Morphology}

Soft part of the feather is easy to handle since it has uniform cross-section bur varying in length which depends upon the location of the soft fibers on the feather. Handling short fibers with varying length was very difficult; hence authors have introduced making nonwovens adopting existing aqueous and spray bonding techniques. Only compression molding method can be used by handling short fibers directly which will be expensive for complicated component manufacturing. Hand layup technique is most popular technique used in an automotive industry, which requires reinforcing material in the form of nonwoven sheet. Hence we proved the aqueous and spray bonded techniques can be effectively used for manufacturing nonwovens.Fig-A6 \& Fig-A78 shows the steps involved in the processing of nonwovens. Non-woven mats prepared by both the methods were proved to be good to prepare layered composite using hand layup technique. Keeping future demand of chicken feather fiber nonwoven mats, other waste products like garden lawn grass and waste paper hand bills were mixed with chicken feather fiber and obtained nonwoven sheets using the same techniques.

From morphological analysis, it was observed that, chicken feather fibers properly mixed with other fibers in an aqueous medium. The microstructure analysis shows that, poultry feathers have hollow in nature so, they can absorb the fluids and non-woven magnified surfaces showed interlocking between the fibers to maintain stability of the mat. Fig-A9 a shows the surface morphology and Fig-A9b represent the cross-sections of the different composition nonwovens.

\section{CONCLUSIONS}

It will be concluded that considering the enormous amount of feather produced in the poultry Industry as a waste material and its low density, it is proposed to use it as a reinforcing material for composites. From the morphological point of view and the presence of hollow structures makes poultry feather fibers to use as a fluid absorbent. Also, concluded that, non-woven produced using $\mathrm{CFF}$ and composition with grass and paper are easy to handle during preparation of complicated components using hand layup technique and can be used for interiors in passenger transportation vehicles. Scope for further work is to test the nonwovens for its physical and mechanical properties. These nonwoven sheets can be used to prepare composites using hand layup technique.

\section{REFERENCES}


[1] Hong and Wool, 2005

[2] According to Indian market research bureau conducted on April $13^{\text {th }} 1994$;

[3] Watt Poultry Guide 2004-05

[4] Martinez-Hernandez, Ana L.; Velasco-Santos, Carlos; De Icaza, Miguel; Castano, Victor M.(2005); Microstructural characterisation of keratin fibres from chicken feathers; International Journal of Environment and Pollution; 23(2), p 162-178

[5] W.F. Schmidt,"(1998) Innovative Feather Utilization Strategies", national Poultry waste Management Symposium Proceedings,

[6] PN-EN ISO 5270: (2011): Fibrous pulps- Laboratory sheets - Estimation of physical properties

[7] P. P. Purslow AND J. F. V. Vincent (1978); Mechanical properties of primary feathers from the Pigeon; exp. Biol., 73, 251-260

[8] Chen C, Chuanbao C, Xilan M, Yin T, Hesun Z(2006). Preparation of non-woven mats from all-aqueous silk fibroin solution with an electrospinning method. Polymer. 47(18): 6322-7

[9] Wdowiak T.(1970) Technology to produce non-woven by a paper-making method (In Polish). Przegląd Papierniczy 94

[10] Saravana Bavan and GC Mohan Kumar,(2010) "Potential use of natural fiber composite materials in India" Journal of Reinforced Plastics and Composites

[11] US Patent 4169706-Method of cleaning poultry feathers

[12] ARONE JR. (2005). Polyethylene/keratin fiber composites with varying polyethylene crystallinity. Composites Part A 36, 1518-1524

[13] Kar, P. and Misra, M. (2004). Use of Keratin Fiber fo $r$ Separation of Heavy Metals from Water, Journal of Chemical Technology and Biotechnology, 79: 13131319

[14] Dweib, M.A., Bullions, T.A., Loos, A.C., Wool, R.P. (2004). Recycled Newspaper and Chicken Feathers as Reinforcement Fiber in Bio-composite Materials. ANTEC 2004 International Conference Proceedings 1478-1481

[15] Feughelman, M. (2002). Natural protein fibers. Journal of Applied Polymer Science, 83: 489-507

[16] Bonser, R.H.C. and Purslow, P.P. (1995). The Young's modulus of feather keratin. Journal of Experimental Biology, 198: 1029-1033.

[17] Cameron, G.J., Wess, T.J., Bonser, R.H.C. (2003). Young's modulus varies with differential orientation of keratin in feathers. Journal of Structural Biology , 143: 118-123.

[18] George, B.R., Bockarie, A., McBride, H., Hoppy, D., Scutti, A. (2003b). Keratin Fiber Nonwovens for APENDIX -A
Erosion Control Natural Fibers, Plastics, and Composites - Recent Advances . Kluwer Academic Publishers. p67-81.

[19] Purslow, P.P. and Vincent, J.F.V.(1978) Mechanical Properties of Primary Feathers from the Pigeon. Journal of Experimental Biology. 72:251-260

[20] Gassner III, G., Schmidt, W.F., Line, M.J., Thomas, C., Waters, R.M. (1998). Fiber and Fiber Products Produced from Feathers. United States Patent \# 5705030

[21] Gentry, R., Kurtis, K., Nanko, H. (2004). Development of Value-Added Products from Chicken Feathers: Paper, Wood Products, and Building Materials. TIP3 Proposal

[22] Chen C, Chuanbao C, Xilan M, Yin T, Hesun Z. (2006)Preparation of non-woven mats from all-aqueous silk fibroin solution with an electrospinning method. Polymer. 47(18): 6322-7

[23] Wrześniewska-Tosik K, Marcinkowska M, Wawro D, Mik T, Pałczyńska M.(2008) Paper-like materials with poultry feather content. P. 386,554. Poland

[24] Kamath, M.G ,Dahiya A,Hegde R,(2004)"Chamical bonding"

[25] Lunenschloss, J and Albrecht, W ,(1985),'Nonwoven Bonded Fabrics",John Wiley \& Sons Inc,

[26] Meazey,A E ,(1971)"Binders used in Bonded Fiber Fabric Production",Nonwovens 71, The textile trade press

[27] Oelkers,J.M, and Sweeney,E.J ,(1988)Latex Binders and Bonding Techniques of Disposables"

[28] Vasanth kumar,Dr.Bhaarathi dhurai"Composite with smart fibrous material"

[29] Text book 'Jones,(1999) Mechanics of composite materials 


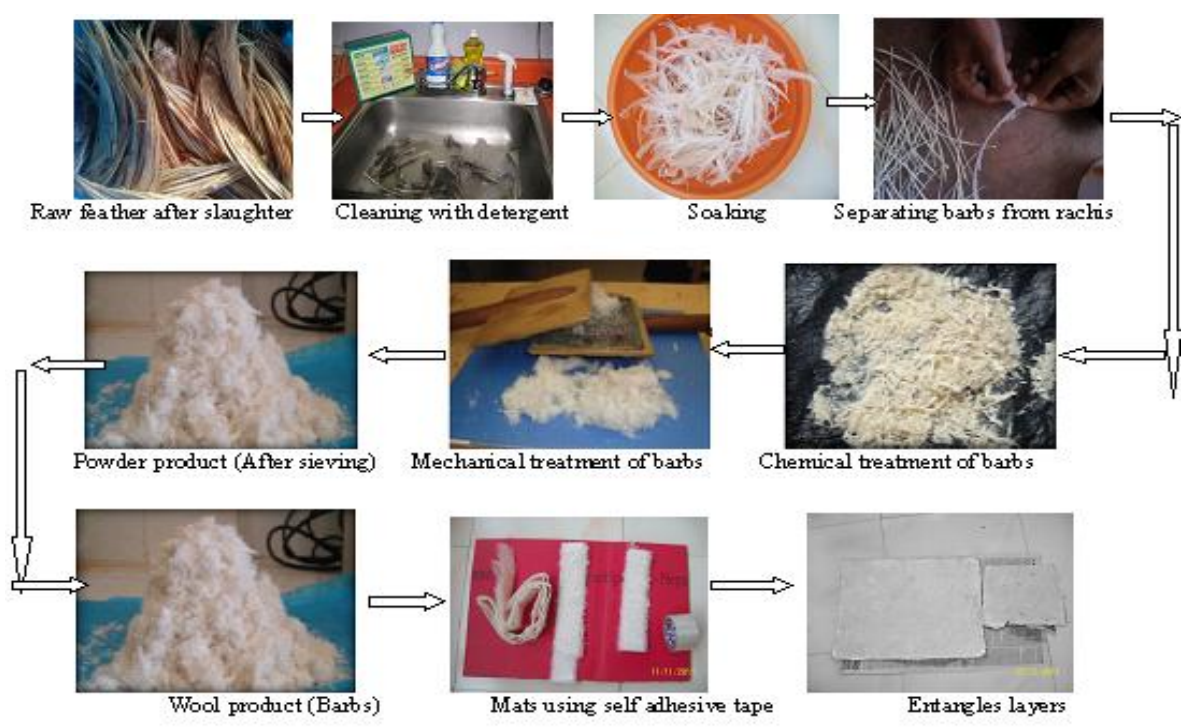

Fig A-1 Flow sheet representing the various treatments of raw poultry feathers to mat
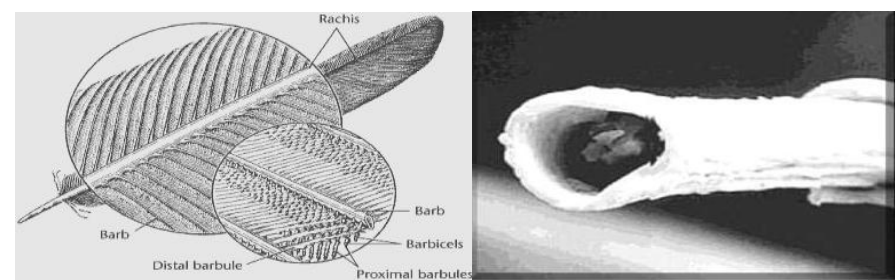

A2- a Terminology of the feather A2-b Cross sectional view of one barb

Fig-A-2 Terminology of the feather

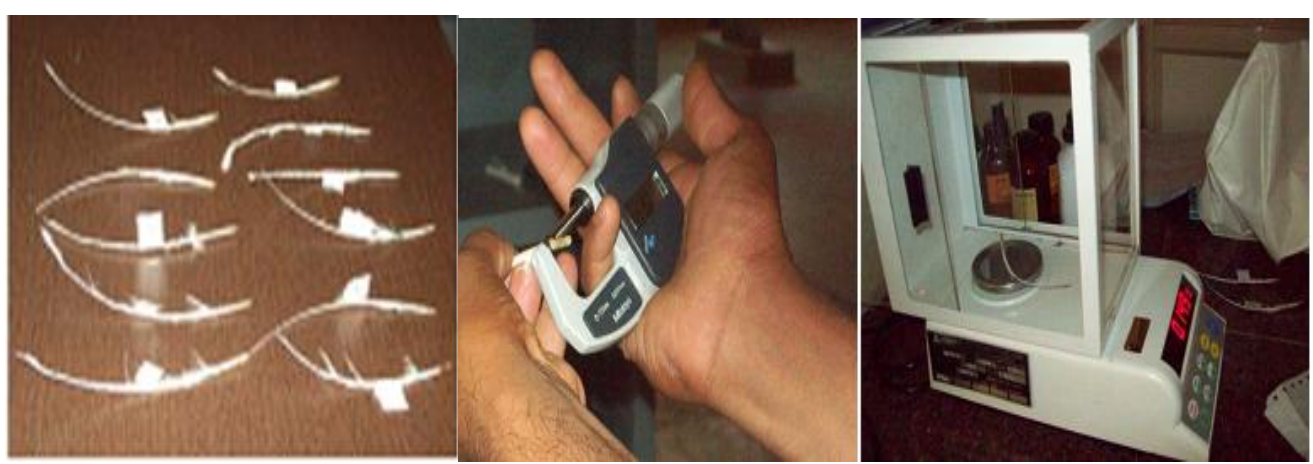

Fig A-3 Quill after striping barbs used for weight and dimension analysis 


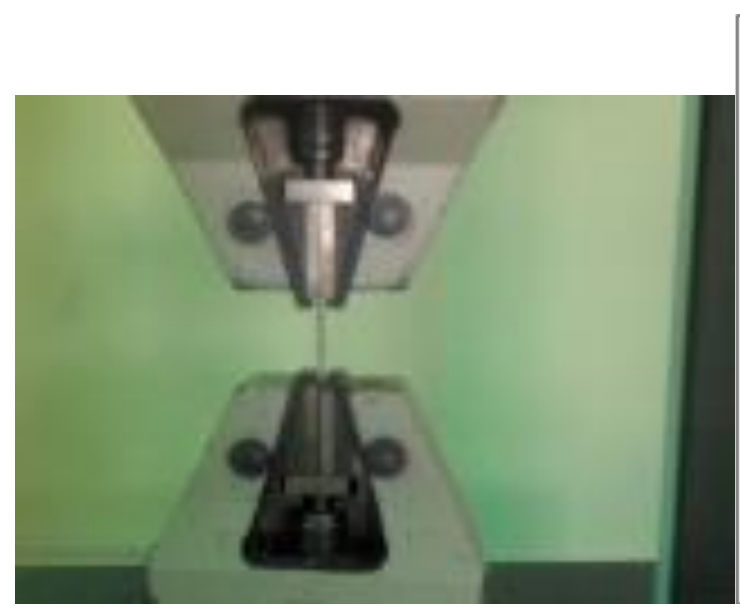

Fig-A4 a Testing arrangement

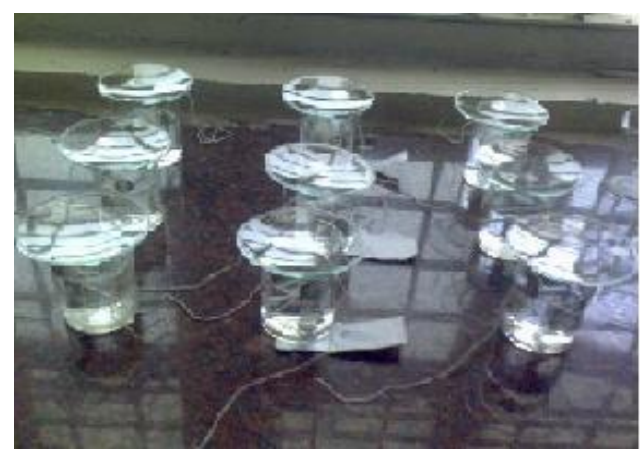

Fig-A5 a Experimental arrangement

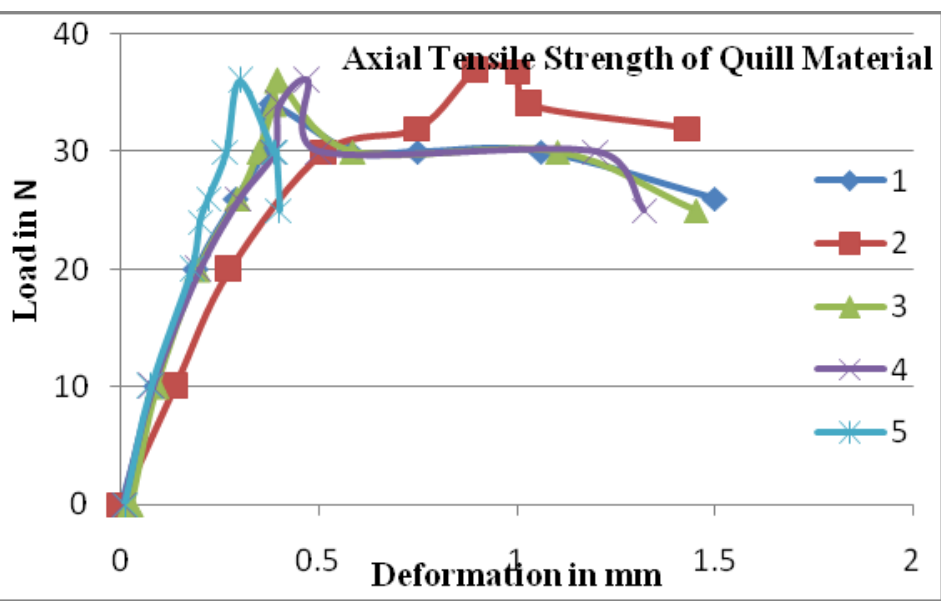

Fig- A4 b Load V/S Deformation

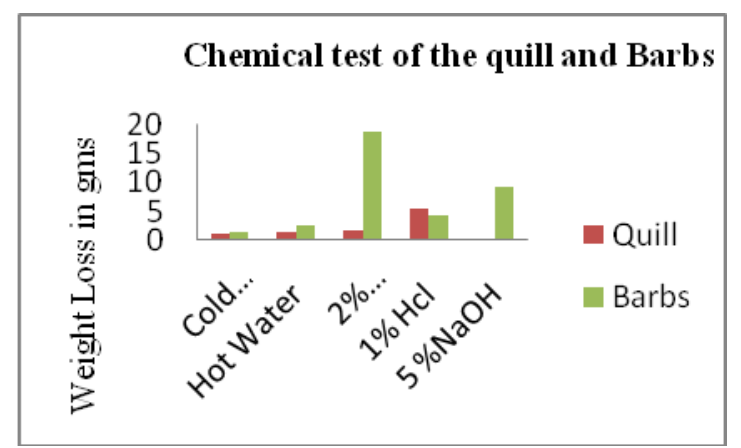

Fig-A5 b Effect of chemicals over weight loss
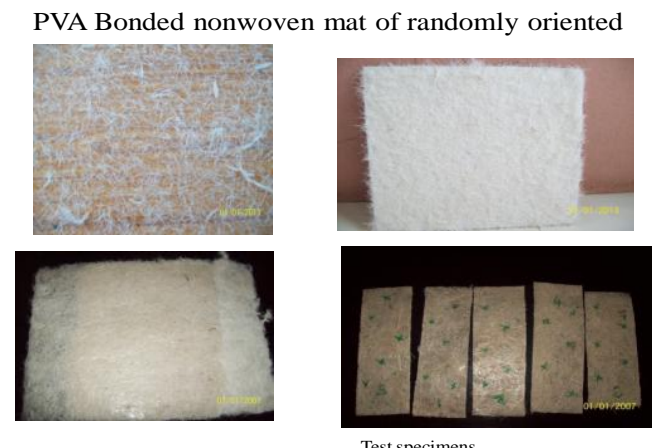

Fig A6 Stages in manufacturing non-woven mat using spray bonding technique 


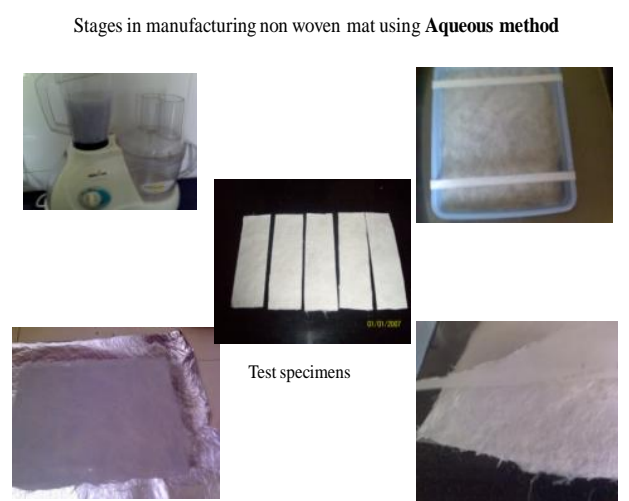

A7a, CFF non-woven mat

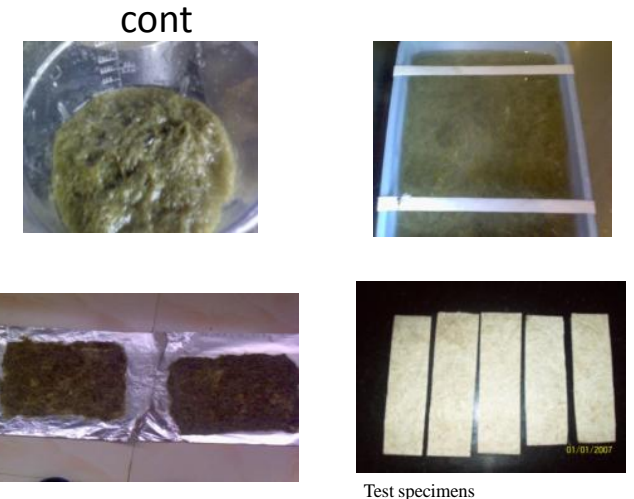

A7b, CFF/Grass/paper non-woven mat

Fig-A7 Stages in manufacturing non woven mat using paper making technique

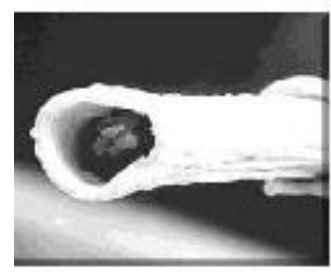

A8a Cross sectional view

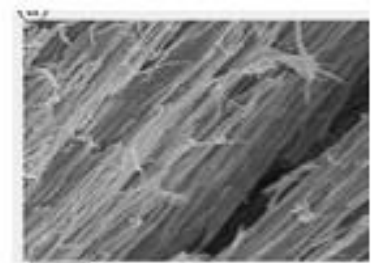

A8b Outer quill

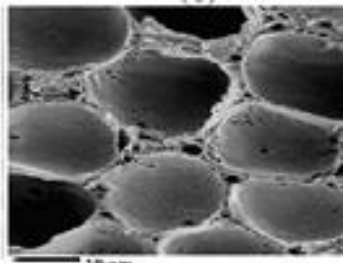

A8c Inner quill of single barb

Fig-A8 (a)-(c), Represents the magnifying surfaces of feather fiber

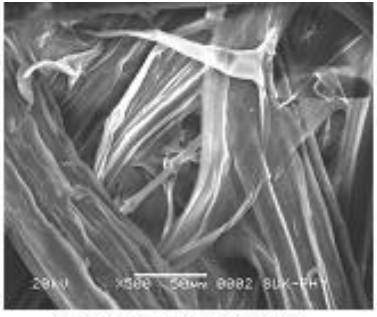

CFF/Grass 50/50 S00X

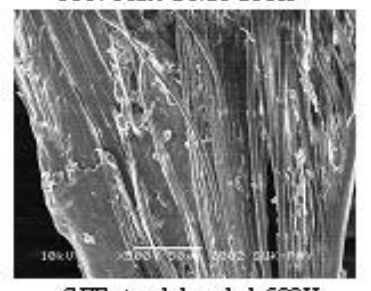

$\mathrm{CFF}$ starch bonded $500 \mathrm{X}$

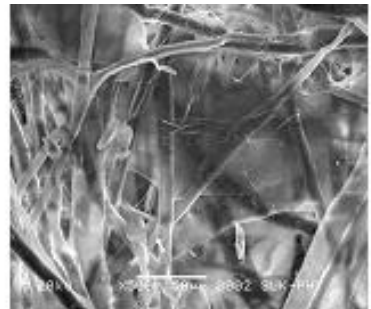

CFF/Paper 50/50 500X

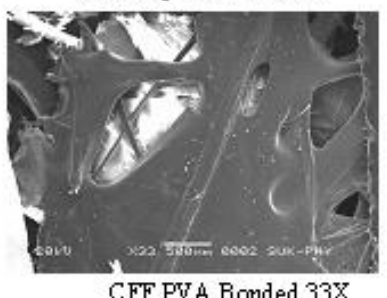

CFF PVA Bonded 33X

Fig-A 9 a Surface images of non-woven mat

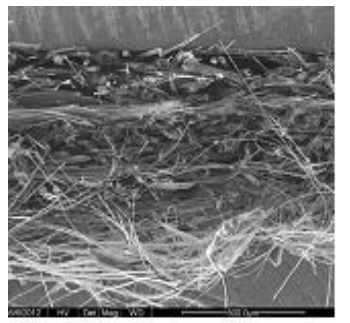

CFF/Grass; $50 \% / 150 \%$

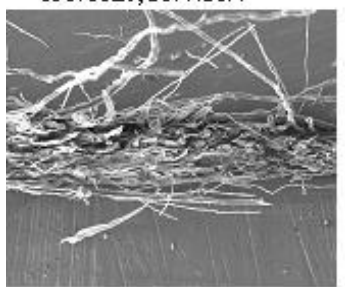

CFF Starch Bonded

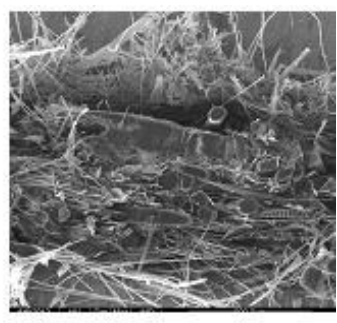

CFF/Paper ; 50\% / 50\%

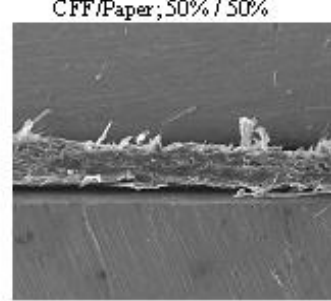

CFF PVA Bonded

Fig- A9 b Cross-section of non-woven mat 


\section{APENDIX-B}

Table.B-1 Calculation of density of chicken feather barbs

\begin{tabular}{|c|c|c|c|c|c|}
\hline $\begin{array}{l}\mathrm{Sl} \\
\text { no. }\end{array}$ & $\begin{array}{l}\text { Glass tube } \\
\text { volume. }(\mathrm{V}) \mathrm{cm}^{3}\end{array}$ & $\begin{array}{l}\text { Weight of the empty } \\
\text { Glass tube. (We) gm }\end{array}$ & $\begin{array}{l}\text { Wt. of the glass tube } \\
\text { filled with } \\
\text { barbs, }(\mathrm{Wb}) . \mathrm{gm}\end{array}$ & $\begin{array}{l}\text { Density of barbs, } \\
=(\mathrm{Wb}-\mathrm{We}) / \mathrm{V} \\
\mathrm{gm} / \mathrm{cc}\end{array}$ & $\begin{array}{l}\text { Mean Density } \\
\mathrm{gm} / \mathrm{cc}\end{array}$ \\
\hline \multicolumn{6}{|c|}{ For test tube of $30 \mathrm{cc}$} \\
\hline 1 & 30 & 21.575 & 43.512 & 0.731 & \multirow{3}{*}{0.7211} \\
\hline 2 & 30 & 21.575 & 42.197 & 0.6874 & \\
\hline 3 & 30 & 21.575 & 43.922 & 0.7449 & \\
\hline \multicolumn{6}{|c|}{ For test tube of $120 \mathrm{cc}$} \\
\hline 4 & 120 & 50.104 & 126.793 & 0.6390 & \multirow{3}{*}{0.677} \\
\hline 5 & 120 & 50.104 & 132.125 & 0.6835 & \\
\hline 6 & 120 & 50.104 & 135.015 & 0.7076 & \\
\hline
\end{tabular}

Table B-2 Experimental results

\begin{tabular}{|c|c|c|c|c|c|c|}
\hline \multirow[b]{2}{*}{ Specimens No } & \multicolumn{4}{|c|}{ Diameters in different locations $\mathrm{mm}$} & \multirow[b]{2}{*}{ Total length in $\mathrm{mm}$} & \multirow[b]{2}{*}{ Weight in $\mathrm{m}$ - gm } \\
\hline & D1 & D2 & D3 & D4 & & \\
\hline 1 & 3.534 & 3.498 & 1.804 & 0.643 & 134 & 0.241 \\
\hline 2 & 3.319 & 3.53 & 1.682 & 0.621 & 153 & 0.278 \\
\hline 3 & 2.909 & 2.64 & 1.363 & 0.667 & 141 & 0.148 \\
\hline 4 & 2.988 & 2.95 & 1.468 & 0.572 & 136 & 0.144 \\
\hline 5 & 3.093 & 3.046 & 1.467 & 0.543 & 150 & 0.162 \\
\hline 6 & 3.55 & 3.070 & 0.897 & 0.362 & 117 & 0.121 \\
\hline 7 & 3.966 & 3.520 & 1.110 & 0.433 & 134 & 0.146 \\
\hline 8 & 2.633 & 2.786 & 1.435 & 0.495 & 138 & 0.143 \\
\hline 9 & 2.663 & 2.577 & 1.377 & 0.470 & 145 & 0.138 \\
\hline
\end{tabular}

Table3 B-3 Experimental results of Quill

\begin{tabular}{|c|l|l|l|l|l|l|}
\hline Sample & $\begin{array}{l}\text { Breaking } \\
\text { load N }\end{array}$ & $\begin{array}{l}\text { Deformation } \\
\text { at Break mm }\end{array}$ & $\begin{array}{l}\text { Tensile } \\
\text { Deformation } \\
\text { at break mm }\end{array}$ & $\begin{array}{l}\text { Average } \\
\text { strain }\end{array}$ & $\begin{array}{l}\text { Average } \\
\text { stress N/mm2 }\end{array}$ & $\begin{array}{l}\text { Young's } \\
\text { modules E Mpa }\end{array}$ \\
\hline 1 & 34.08 & 0.3759 & 0.3759 & 0.034605 & 6.000509 & 173.4 \\
\hline 2 & 36.91 & 0.8960 & 0.8960 & 0.044674 & 6.546035 & 146.53 \\
\hline 3 & 36.02 & 0.395 & 0.395 & 0.03242 & 6.127638 & 189.007 \\
\hline 4 & 36.00 & 0.47 & 0.47 & 0.032387 & 6.127638 & 189.2 \\
\hline 5 & 36.00 & 0.34 & 0.34 & 0.01614 & 5.873379 & 363.9 \\
\hline Max. & $\mathbf{3 6 . 9 1}$ & $\mathbf{0 . 8 9 6 0}$ & $\mathbf{0 . 8 9 6 0}$ & 0.044674 & 6.546035 & 363.9 \\
\hline Min. & $\mathbf{3 4 . 0 9}$ & $\mathbf{0 . 3 4}$ & $\mathbf{0 . 3 4}$ & 0.01614 & 5.873379 & 173.4 \\
\hline
\end{tabular}

Table No B-4 Chemical test of the quill and barbs

\begin{tabular}{|l|l|l|l|}
\hline SL.No & \multicolumn{1}{|c|}{ Particulars } & Quill fiber after 24hrs drying & \multicolumn{1}{|c|}{ Barbs after 24hts drying } \\
\hline 01 & Cold Water & $1.1 \%$ Weight loss & $1.52 \%$ weight loss \\
\hline 02 & Hot Water & $1.5 \%$ Weight loss & $2.56 \%$ weight loss \\
\hline 03 & With 2\% $\mathrm{Na}_{2} \mathrm{CO}_{3}$ (Washing Soda) & $1.64 \%$ Weight loss & $18.877 \%$ Weight loss \\
\hline 04 & With 1\% $\mathrm{Hcl}$ (Hydrochloric acid) & $5.65 \%$ weight loss & $4.494 \%$ Weight loss \\
\hline 05 & With 5\% NaOH (Sodium Hydroxide) & Completely dissolved & $9.14 \%$ Weight loss * \\
\hline
\end{tabular}


Table B-5 Observation of burning behaviour

\begin{tabular}{|c|c|c|c|c|c|c|}
\hline \multirow[t]{2}{*}{ Sl.No } & \multirow[t]{2}{*}{ Description } & \multicolumn{3}{|c|}{ Burning Behaviour } & \multirow[b]{2}{*}{ Residue } & \multirow[b]{2}{*}{ Odour } \\
\hline & & $\begin{array}{l}\text { When approached } \\
\text { Flame }\end{array}$ & $\begin{array}{l}\text { When in the } \\
\text { Flame }\end{array}$ & $\begin{array}{l}\text { Removed from } \\
\text { the Flame }\end{array}$ & & \\
\hline 1 & Central quill & Fuses & Fuses and Burns & $\begin{array}{l}\text { Supports } \\
\text { combustion for } \\
\text { a long time }\end{array}$ & $\begin{array}{l}\text { Easily } \\
\text { crushable. } \\
\text { Black } \\
\text { Soft ash }\end{array}$ & $\begin{array}{l}\text { Burning } \\
\text { rubber }\end{array}$ \\
\hline 2 & Barbs & Fuses & Fuses and burns & $\begin{array}{l}\text { Supports } \\
\text { combustion for } \\
\text { a short time }\end{array}$ & $\begin{array}{l}\text { Completely } \\
\text { Fuses }\end{array}$ & $\begin{array}{l}\text { Burning } \\
\text { Hair }\end{array}$ \\
\hline
\end{tabular}

